\title{
Identification and characterization of novel small RNAs in the aspS-yrvM intergenic region of the Bacillus subtilis genome
}

\author{
Satoru Suzuma, ${ }^{1}$ Sayaka Asari, ${ }^{1}$ Keigo Bunai, ${ }^{1}$ Keiko Yoshino, ${ }^{1}$ \\ Yoshinari Ando, ${ }^{1}$ Hiroshi Kakeshita, ${ }^{1}$ Masaya Fujita, ${ }^{2}$ Kouji Nakamura ${ }^{1}$ \\ and Kunio Yamane ${ }^{1}$
}

Author for correspondence: Kouji Nakamura. Tel: +8129853 6419. Fax: +81298537723. e-mail: nakamura.kouji@nifty.ne.jp

\footnotetext{
1 Institute of Biological Sciences, University of Tsukuba, Tsukuba-shi, Ibaraki 305-8572, Japan

2 Department of Molecular and Cellular Biology, The Biological Laboratories, Harvard University, 16 Divinity Avenue, Cambridge, MA 01238, USA
}

\begin{abstract}
A novel RNA species was isolated from Bacillus subtilis, and its sequence was determined and mapped to its genetic position. This RNA was termed BS190 RNA from the length of its mature form (190 $\mathrm{nt}$ ), and the gene encoding it is located within the aspS-yrvM intergenic region of the $B$. subtilis genome. Northern blotting revealed that the novel RNA species is transcribed in vegetative cells as a larger precursor (BS201 RNA, $201 \mathrm{nt}$ ). After transcription, the $5^{\prime}$ end of the precursor is processed to generate the mature form, BS190 RNA. A computer-aided prediction of the secondary structure of BS190 RNA showed that it can be folded into a single hairpin structure with some bulge structures. The authors found that the growth rate of a $\triangle B S 190$ mutant strain of $B$. subtilis was reduced when compared to the wild-type. A phylogenetic comparison of the sequence of the BS190 RNA gene with sequences from the databases suggests that RNA related to BS190 RNA appears to be encoded in the genomes of Bacillus halodurans and Listeria monocytogenes.
\end{abstract}

Keywords: non-coding RNA, RNA processing, RNA secondary structure

\section{INTRODUCTION}

Bacterial and eukaryotic cells contain small RNAs (sRNAs) that are not translated (Wassarman et al., 1999; Wightman et al., 1993; Lankenau et al., 1994). These sRNAs function as RNA molecules instead of encoding proteins. Non-coding sRNA genes are quite numerous and their functions vary (Eddy, 1999; Erdman et al., 2001; Storz, 1999). Most of these non-coding sRNAs can be defined as regulatory molecules that seem to fine-tune the cellular responses to stress by integrating environmental signals into global regulation (Altuvia et al., 1997; Zhang et al., 1998). sRNAs act via several mechanisms, such as RNA-RNA base-pairing, RNAprotein interactions and intrinsic RNA activity (Altuvia \& Wagner, 2000; Wassarman \& Storz, 2000; Kirsebom, 2001); they also regulate diverse cellular functions, including RNA processing, mRNA stabilization, translation, protein stabilization and protein secretion. At least 10 sRNAs are encoded within the Escherichia coli

Abbreviations: scRNA, small cytoplasmic RNA; sRNA, small RNA; tmRNA, transfer-message RNA. genome (Wassarman et al., 1999). Recently, Wassarman et al. (2001) used sequence conservation coupled with micro-array expression analysis to identify 17 new noncoding RNAs in E. coli. Argaman et al. (2001) used sequence conservation coupled with promoter and $\rho$ independent terminator prediction and identified 14 new non-coding RNAs in the same species. Moreover, Rivas et al. (2001) predicted 275 candidates for structural RNA loci in E. coli using computational analysis and empirically found that at least 11 loci express small, apparently non-coding RNAs. Extensive experimental characterization of the new loci is now under way.

Signal recognition particle (SRP) RNA is involved in the translocation of proteins across the endoplasmic reticulum (Stroud \& Walter, 1999). SRP RNAs are ubiquitous in nature and contain evolutionarily conserved structural features (Poritz et al., 1988; Gorodkin et al., 2001). The 4.5S RNA of E. coli and the small cytoplasmic RNA (scRNA) of Bacillus subtilis belong to a family of SRP RNAs that function in protein secretion as an integrated component of the SRP-like particle along with an Ffh protein that is a homologue of one of the mammalian SRP components, SRP54 (Bernstein et al., 


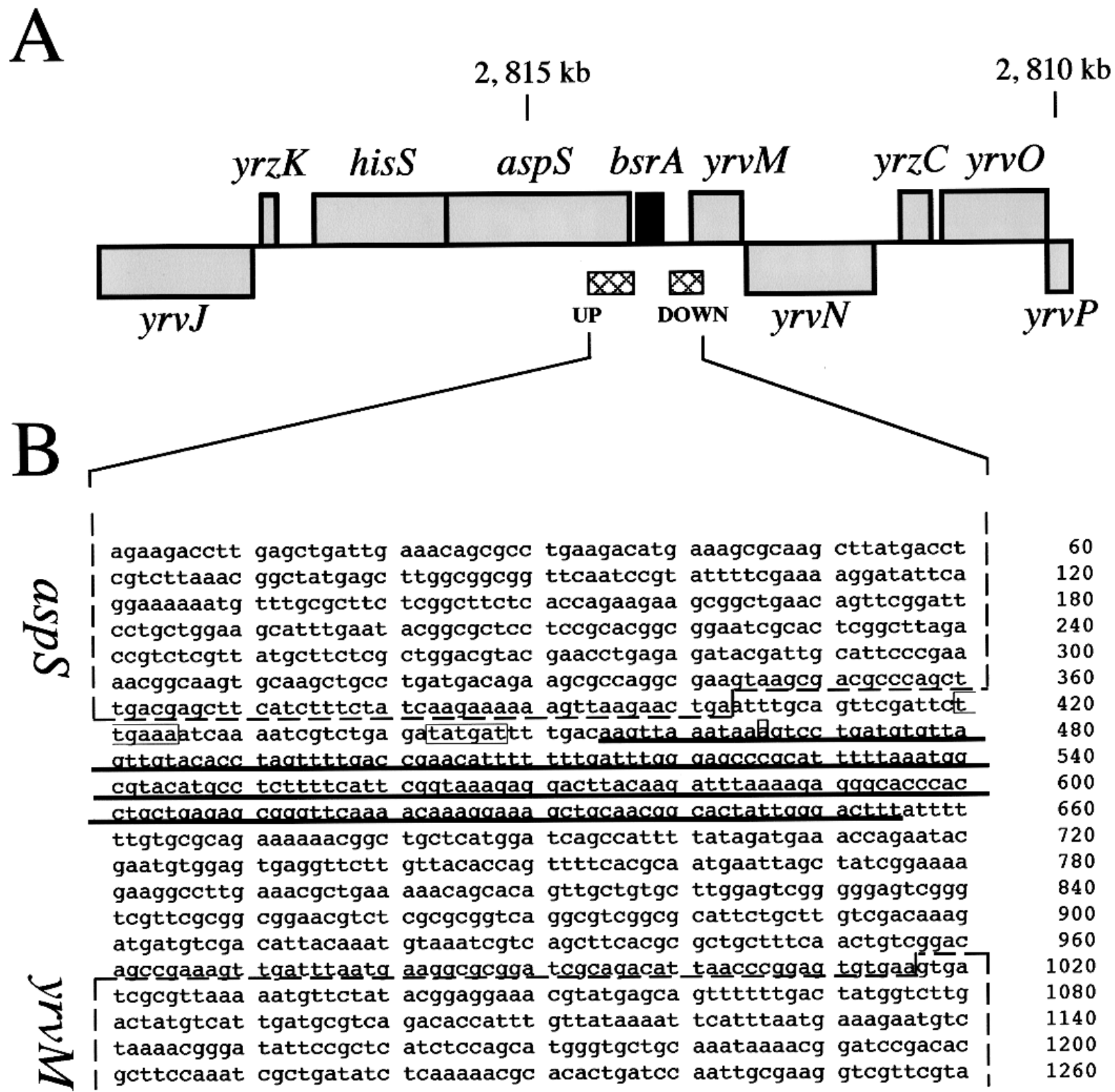

Fig. 1. Mapping and sequencing of the aspS-yrvM intergenic region. (A) Schematic representation of the organization of the genomic region around the BS190 RNA gene. Solid box, the gene encoding BS190 RNA (bsrA); cross-hatched boxes, upstream (UP) and downstream (DOWN) DNA fragments used to construct the BS190 RNA null-mutant strain ( $\triangle B S 190$ RNA). Numbering is according to that of the $B$. subtilis whole-genome database and shows the distance from the origin of replication. (B) Nucleotide sequence of a $0.9 \mathrm{~kb}$ DNA fragment that includes the BS190 RNA gene (bsrA). The RNAcoding region corresponds to nucleotide positions 18815-18626 in the $B$. subtilis whole-genome database (GenBank accession no. Z99118). The region encoding BS201 RNA is underlined. The nucleotide at the $5^{\prime}$ end of BS190 RNA, as determined by primer extension, is boxed (a). Two ORFs that are equivalent to portions of the aspS and yrvM genes are enclosed by dotted lines. Possible promoter sequences $(-35$ and -10$)$ at the front of the BS190 RNA gene are enclosed by boxes.

1989). However, the earliest defect seen in cells conditionally depleted of 4.5S RNA or scRNA is the inhibition of protein synthesis - both RNA molecules are normally associated with ribosomes (Brown, 1987; Bourgaize \& Fournier, 1987; Nakamura et al., 1999). These results suggest a role for scRNA and 4.5S RNA in translation. Elongation factor $\mathrm{G}(\mathrm{EF}-\mathrm{G})$ is a $4.5 \mathrm{~S}$ RNA-binding protein, and a depletion of 4.5S RNA causes an increase in the amount of EF-G associated with ribosomes, suggesting that $4.5 \mathrm{~S}$ RNA is involved in EF-G recycling (Brown \& Fournier, 1984; Jovine et al., 2000; Shibata et al., 1996). Therefore, 4.5S RNA affects both protein synthesis and secretion, but the exact mechanism of its action in each pathway is, as yet, unclear. 
In contrast to $E$. coli, only three sRNAs besides $5 \mathrm{~S}$ rRNA and tRNAs have been identified in B. subtilis. Genomic sequence data and new algorithms have allowed the development of systematic screens for non-coding sRNA genes (Le et al., 1989; Chen et al., 1990; Dandekar \& Hentze, 1995; Lowe \& Eddy, 1997). The present study identifies and characterizes two novel sRNAs in $B$. subtilis-named BS190 RNA and BS201 RNA - and shows that the smaller, mature BS190 RNA is generated by processing its precursor, BS201 RNA, at the $5^{\prime}$ end. This study also shows that a reduction in the level of BS190 RNA expression leads to defective vegetative growth.

\section{METHODS}

Bacterial strains. B. subtilis 168 (trpC2) was used to construct a $\triangle$ BS190 RNA strain (a mutant with a BS190 RNA gene deletion).

Preparation and purification of RNAs from $B$. subtilis. Total RNA was isolated from frozen cells essentially as described by Sambrook et al. (1989) and Nuyts et al. (2001). Frozen cells $(0.1 \mathrm{~g}$, wet weight $)$ were vigorously shaken in $2 \mathrm{ml}$ phenol/ chloroform $(1: 1, \mathrm{v} / \mathrm{v})$ containing $2.4 \mathrm{~g}$ glass beads. Total RNA was loaded into the wells of $6 \%$ denaturing polyacrylamide gels (48 cm height) in $6 \mathrm{M}$ urea and then resolved by electrophoresis for $14 \mathrm{~h}$ at $500 \mathrm{~V}$. After this time, the gels were stained with ethidium bromide and visualized under a UV light. Two bands of about $200 \mathrm{nt}$ in size (estimated by comparison with molecular markers) were excised from the gels and dialysed against $0.8 \mathrm{ml}$ of $0.5 \times$ TBE buffer $[45 \mathrm{mM}$ Tris/ $\mathrm{HCl}$ (pH 8.0), $45 \mathrm{mM}$ boric acid, $1 \mathrm{mM}$ EDTA]. RNAs were electro-eluted from the gel and purified as described above.

Cloning and sequencing of the BS190 RNA and BS201 RNA genes. Both the BS190 RNA and the BS201 RNA, which had been purified from denaturing polyacrylamide gels and polyadenylated at their $3^{\prime}$ termini using poly(A) polymerase (Takara-Shuzo), were used as templates for the reverse transcription of single-stranded DNA copies using the oligomer $(\mathrm{dT})_{25}$ as a primer. The first strand of DNA was synthesized using RNA-dependent DNA polymerase (reverse transcriptase; Takara-Shuzo). The product of the first-strand synthesis was treated with RNase H (Takara-Shuzo), and the second strand of DNA was constructed using E. coli DNA polymerase I (Takara-Shuzo). The DNA fragment generated was purified and then inserted into the HincII site of pUC118. The hybrid plasmid was used to transform E. coli JM109 as described above. Clones containing the BS190 RNA gene or the BS201 RNA gene were designated pTUE190 and pTUE201, respectively. Both strands of the DNA fragment were shotgun sequenced by chain termination using the Dye Terminator Cycle Sequencing Kit (Applied Biosystems). The two gene fragments that were cloned into pTUE190 and pTUE201 covered the $5^{\prime}$ ends of BS190 RNA and BS201 RNA, respectively, according to a comparison with the $5^{\prime}$ end of each RNA determined by primer extension.

Mapping the $5^{\prime}$ ends of the BS190 RNA and BS201 RNA genes. This was done by primer extension. Primer P1 (5'CGCCATTTAAAAATGCGGGC-3' ; positions 542-523, Fig. 1B) was labelled by $5^{\prime}$-end phosphorylation using $\left[\gamma^{32} \mathrm{P}\right]$ ATP in the presence of polynucleotide kinase (TOYOBO); the subsequent extension was done essentially as described previously (Nakamura et al., 1994) in a reaction mixture containing 1 pmol of labelled P1, 10-90 $\mu \mathrm{g}$ of total RNA or
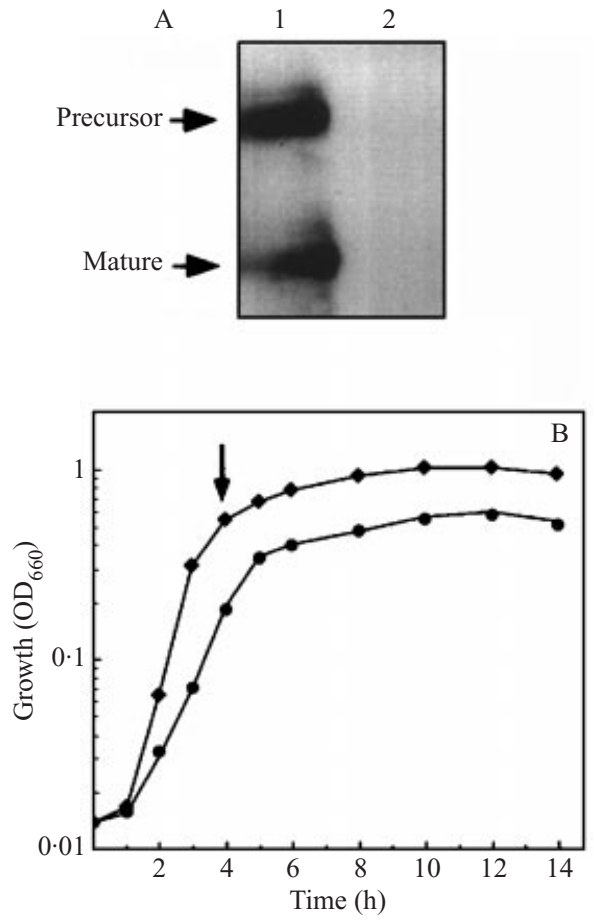

Fig. 2. Effects of $B S 190$ RNA depletion on cell growth. (A) Northern blots of BS201 RNA (precursor) and BS190 RNA (mature). Total RNAs were prepared from both the wild-type (lane 1) and the $\triangle B S 190$ RNA (lane 2) strains at $4 \mathrm{~h}$ after inoculation [indicated by an arrow in (B)]. The transcripts (precursor and mature) were identified based on their sizes. (B) Growth curves of the wild-type strain $(\diamond)$ and the $\triangle \mathrm{BS} 190$ RNA strain (O) in LB broth at $37^{\circ} \mathrm{C}$.

$0 \cdot 2 \mu \mathrm{g}$ of gel-purified RNA, $1 \mathrm{mM}$ of each dNTP and $25 \mathrm{U}$ of AMV reverse transcriptase (Takara-Shuzo) in $20 \mu \mathrm{l}$ of the buffer supplied by the manufacturer. The oligonucleotide and the RNA were mixed and then ethanol precipitated. The precipitate was resuspended in $10 \mu \mathrm{l}$ TE buffer [Tris $/ \mathrm{HCl}$ ( $\mathrm{pH} 7 \cdot 5), 1 \mathrm{mM}$ EDTA] and incubated at $70{ }^{\circ} \mathrm{C}$ for $5 \mathrm{~min}$ and slowly cooled to $42{ }^{\circ} \mathrm{C}$. The other components of the reaction mixture were added to the suspension, and the mixture was incubated at $42{ }^{\circ} \mathrm{C}$ for $60 \mathrm{~min}$. The reaction was stopped by a 5 min incubation at $95^{\circ} \mathrm{C}$. Formamide loading buffer was added to the samples; the reaction products were then separated through polyacrylamide sequencing gels containing $6 \mathrm{M}$ urea. The gels were dried and the bands were visualized by autoradiography. Primer-extension products were identified on the gels by comparing the bands generated with those of sequencing reactions generated with the same labelled oligonucleotide and a Sequencing Kit (Takara-Shuzo). The templates for sequencing reactions were M13 phage clones containing the wild-type B. subtilis BS190 RNA gene.

Sucrose-gradient centrifugation. Vegetative cells (2 g wet weight) were collected by centrifugation and homogenized with sand quartz in $20 \mathrm{ml}$ of buffer A [ $50 \mathrm{mM}$ TEA (pH 8.0), $5 \mathrm{mM} \mathrm{Mg}\left(\mathrm{CH}_{3} \mathrm{COO}\right)_{2}, 0.5 \mathrm{mM}$ PMSF, $\left.1 \mathrm{mM} \mathrm{DTT}\right]$. The homogenate was centrifuged in COREX tubes $(30 \mathrm{ml})$ at $12000 \mathrm{~g}$ for $10 \mathrm{~min}$. The supernatant was then loaded into a $5-20 \%$ sucrose density gradient prepared in buffer A and separated by centrifugation at $60000 \mathrm{~g}\left(8 \mathrm{~h}\right.$ at $\left.4^{\circ} \mathrm{C}\right)$ using a Beckman SW41Ti rotor. Samples were collected from the top of the gradient as 21 fractions of $500 \mu \mathrm{l}$ each; the polysomal 


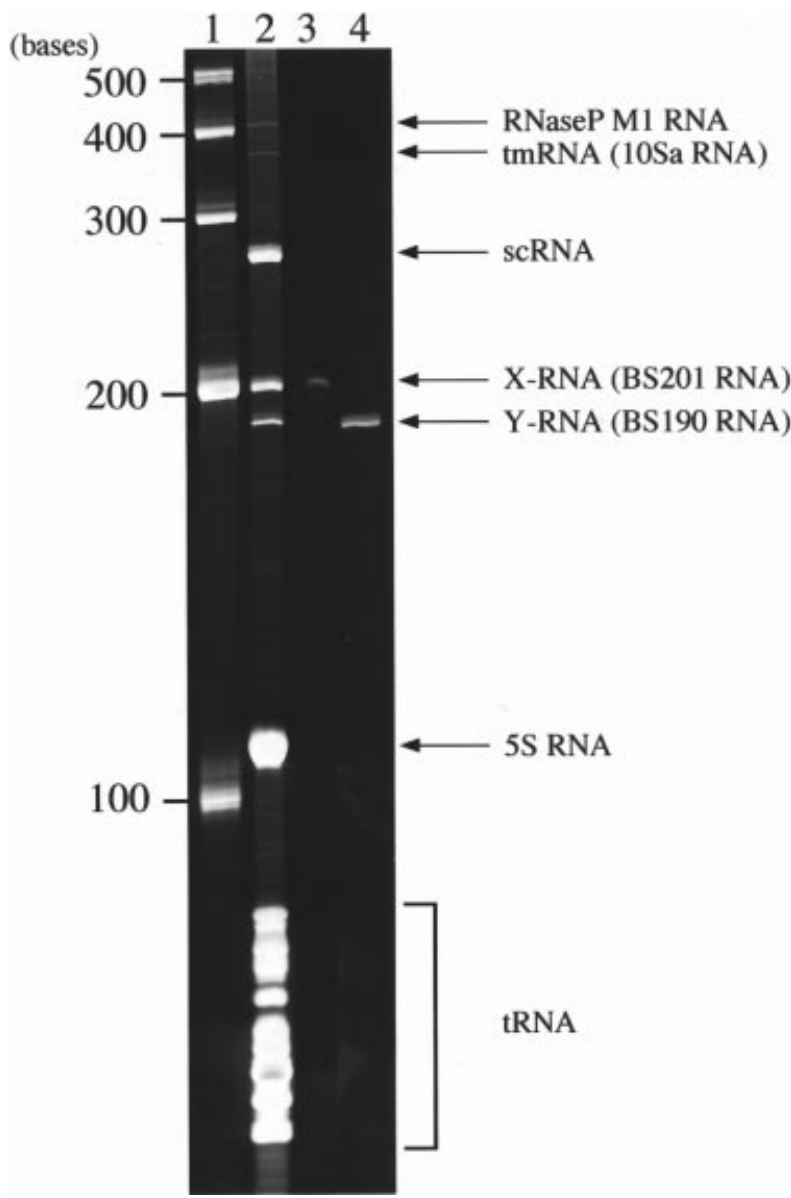

Fig. 3. Detection of sRNA species from B. subtilis 168 (trpC2). Total RNA was isolated as described in Methods, then separated through a $6 \%$ polyacrylamide gel under denaturing conditions (lane 2). The two unidentified bands (X-RNA and Y-RNA) were purified from the gel and resolved by electrophoresis (lanes 3 and 4). The identities of the transcripts (RNaseP M1 RNA, tmRNA, scRNA and 55 rRNA) were based on their size and responses to DNA probes encoding each RNA gene in Northern blots (data not shown). Lane 1, molecular mass marker.

fraction was recovered from the bottom of the tube. Aliquots $(400 \mu \mathrm{l})$ of each fraction were extracted with phenol/chloroform/isoamyl alcohol $(24: 24: 1, \mathrm{v} / \mathrm{v} / \mathrm{v})$ and precipitated with 2 vols ethanol. The RNAs were collected and dried for Northern hybridization.

Northern blotting. RNA was isolated from cell lysates prepared from B. subtilis cells at the vegetative phase of growth. After electrophoresis on a sequencing gel, the RNA was electrotransferred onto Gene Screen nylon membranes (NEN Research Products) and hybridized with the $5^{\prime}$-end ${ }^{32} \mathrm{P}-$ labelled 300 bp DNA fragment containing the BS190 RNA coding sequence that was amplified by using the synthetic primers P3 (5'-ATTTGCAGTTCGATTC-3') and P4 $\left(5^{\prime}-\right.$ ATAAAATGGCTGATCC-3').

Construction of the deletion mutant. The $\triangle \mathrm{BS} 190$ RNA mutant strain was constructed as follows. A 378 bp fragment (UP; from +48 to +411 , Fig. 1B) of the BS190 RNA locus, including the $3^{\prime}$ region of aspS, and a $576 \mathrm{bp}$ fragment (DOWN; from +663 to +1218 , Fig. 1B) in front of the $5^{\prime}$

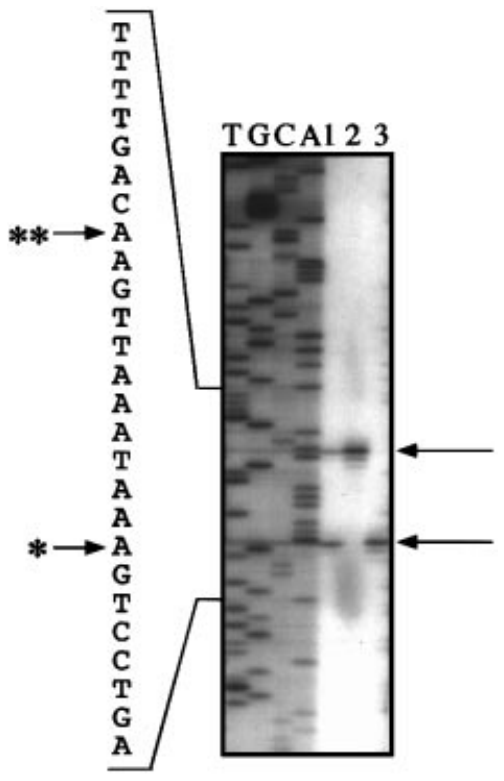

Fig. 4. Determination of the $5^{\prime}$ ends of $B$. subtilis BS201 RNA and BS190 RNA. Lanes T, G, C and A show DNA sequence ladders primed with the oligonucleotide used for the primer extension of RNA from $B$. subtilis. Total RNA samples were prepared from $B$. subtilis 168 ( $\operatorname{trp} C 2$ ) that had been cultured for $4 \mathrm{~h}$ after inoculation (lane 1). Gel-purified BS190 RNA and BS201 RNA were also analysed (lanes 2 and 3) using the same primer. Primer-extension products for the BS190 RNA and BS201 RNA are indicated by arrows. The positions in the DNA sequence ladder of the non-coding strand corresponding to the $5^{\prime}$ terminus of BS201 RNA (**) and BS190 RNA (*) are indicated.

region of $y r v M$ were amplified from $B$. subtilis chromosomal DNA using $\mathrm{P}_{\text {up }}-1$ (5'-GATCAAGCTTATGACCTCGTCTTAAAC- $\left.3^{\prime}\right)$ and $\mathrm{P}_{\text {up }}-2$ (5'-GATCGAATTCCTGCAAATTCAGTTCTTAAC- $\left.3^{\prime}\right)$, and $\mathrm{P}_{\text {down }}-1$ (5'-GATCGAATTCGTGCGCAGAAAAAACGGCTG-3') and $\mathrm{P}_{\text {down }}-2$ (5'-GATCGGATCCTATCAGCGATTTGGAAGC-3'), respectively (Fig. 1). After amplification, the UP fragment was digested with HindIII and EcoRI and the DOWN fragment was digested with EcoRI and BamHI - restriction sites for these enzymes were located within each primer used for PCR (shown in bold). The two fragments were ligated and inserted into the HindIII and BamHI sites of pBluescript II SK${ }^{-}$. The resulting recombinant plasmid DNA was digested with EcoRI and then ligated with a kanamycin-resistance cassette that was prepared from pDG783 (Guerout-Fleurgy et al., 1995) by digestion with EcoRI. Plasmid DNA from positive clones selected in E. coli for kanamycin-resistance were isolated. The DNA fragment containing the BS190 RNA gene locus in which the BS190 RNA gene was replaced with the kanamycin-resistance gene was isolated by PCR using primers $P_{\text {up }}-1$ and $P_{\text {down }}-2$ and used to transform competent $B$. subtilis wild-type cells. Isolates exhibiting kanamycin-resistance resulted from double-crossover events and were confirmed by Southern hybridization (data not shown). Northern blots demonstrated the absence of BS190 RNA in these isolates (Fig. 2A), which were referred to as the $\triangle \mathrm{BS} 190 \mathrm{RNA}$ mutant.

In vitro synthesis of ${ }^{32} \mathrm{P}$-labelled BS190 RNA. The 215 bp DNA fragment encoding BS190 RNA was amplified using two oligonucleotides, 5'-GTACAAGCTTTAAAGTCCTGATGTGTTAGT-3' and 5'-GATCGGATCCAAAGTCCCAATA- 
GTGCCGTT-3'. These two oligonucleotides were designed to create HindIII and BamHI sites at the $5^{\prime}$ and $3^{\prime}$ ends of the PCR product (shown in bold). This fragment was digested with HindIII and BamHI, and inserted into the HindIII$B a m$ HI sites of the pGEM-3Zf $(+)$ vector (Promega). The resulting plasmid was linearized by digestion with $B a m \mathrm{HI}$ and used as the template for transcription. BS190 RNA was synthesized using $50 \mathrm{U}$ of SP6 RNA polymerase (TakaraShuzo) and Riboprobe System Buffers (Promega) in the presence of $10 \mu \mathrm{Ci}(370 \mathrm{kBq})$ of $\left[\alpha^{-32} \mathrm{P}\right] \mathrm{CTP}$ (Amersham Pharmacia Biotech). The product was precipitated with ethanol, dissolved in sterile de-ionized water and renatured by a $10 \mathrm{~min}$ incubation at $70^{\circ} \mathrm{C}$ followed by slowly cooling to room temperature.

\section{RESULTS AND DISCUSSION}

\section{Identifying sRNAs}

We attempted to isolate and characterize novel sRNAs with unknown functions in B. subtilis. Several distinct bands of $<500 \mathrm{nt}$ were detectable in total RNA. We assigned several known species of sRNAs, such as scRNA, M1 RNA (component of RNase P) and tmRNA, to individual bands by Northern blotting (data not shown). Two RNAs that migrated close together were clearly separated at around the $200 \mathrm{nt}$ mark (Fig. 3, lane 2 ). Based on the migration of the size markers used, we estimated that the lengths of these two RNAs were 190 and $201 \mathrm{nt}$. That these molecules were indeed RNAs was confirmed by incubating the separation gel with RNase in the presence of $25 \mathrm{mM}$ EDTA: this caused the disappearance of the BS190 and BS201 RNA bands and of all the other bands (data not shown). The two new RNA species were named BS190 RNA (190 nt) and BS201 RNA (201 nt). To map the gene encoding them on the genome, the two RNAs were isolated separately from denaturing $6 \%$ polyacrylamide gels (Fig. 3, lanes 3 and 4). A polyadenylation tail was added to the RNAs using poly(A) polymerase, then two DNA fragments complementary to BS190 RNA and BS201 RNA were constructed, cloned into pUC118 and sequenced. The coding region of BS190 RNA is completely included in that of the BS201 RNA, and it was shown to be located within the aspS-yrv $M$ intergenic region on the $B$. subtilis genome (Fig. 1A). The $3^{\prime}$ ends of the two RNAs were identical, as judged from the cDNA sequence located immediately before the poly(A) tail. Conversely, the $5^{\prime}$ end of BS201 RNA was located 11 nt upstream of that of BS190 RNA (Fig. 4). These mapping data confirmed that
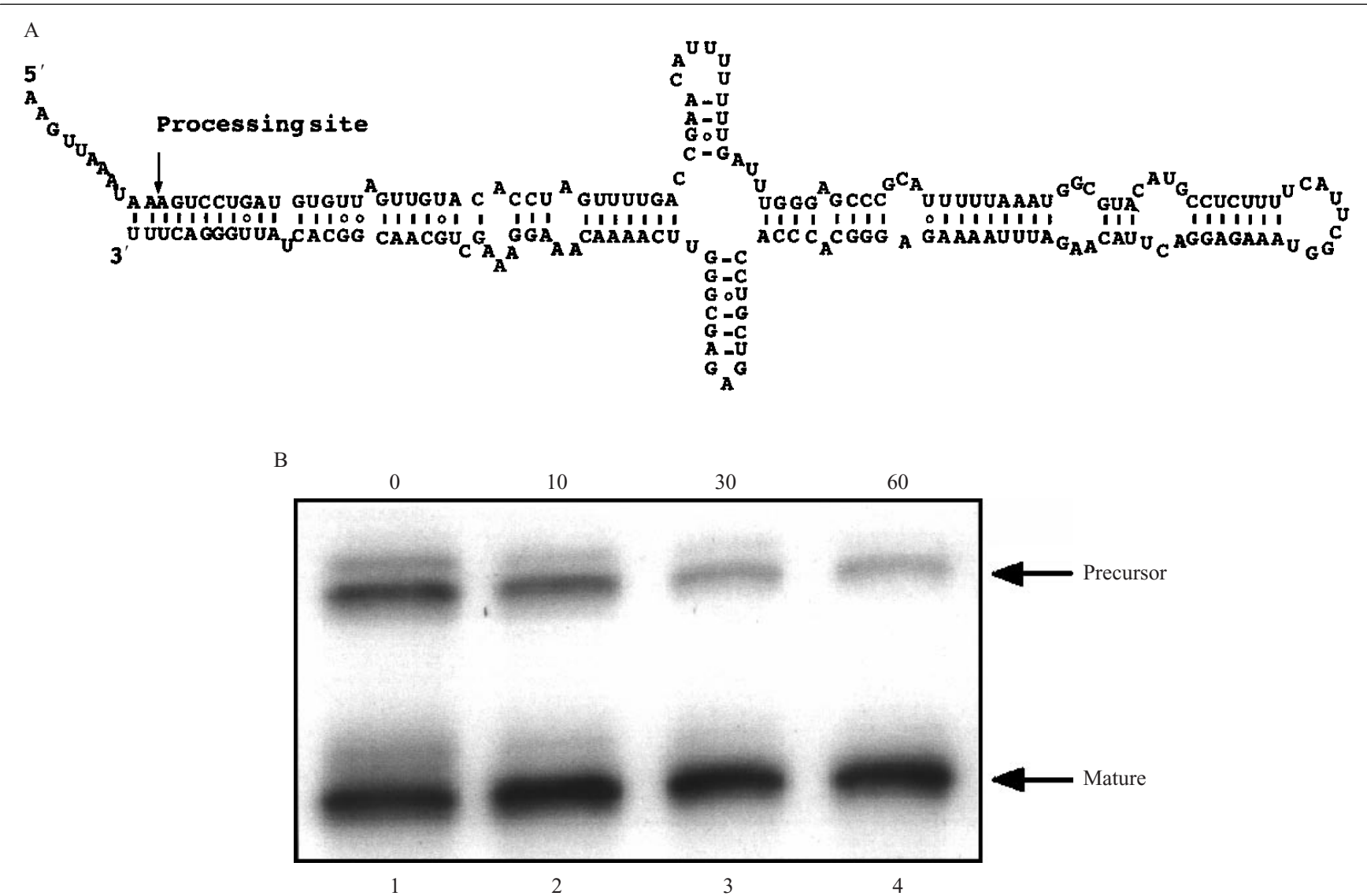

Fig. 5. Processing of BS201 RNA to generate BS190 RNA. (A) The potential secondary structure of the predicted sequence of BS201 RNA. G-U base-pairs are indicated by $O$. (B) Northern blots showing the steady-state levels of BS201 RNA (precursor) and BS190 RNA (mature) in exponentially growing wild-type B. subtilis. Rifampicin (300 $\left.\mu \mathrm{g} \mathrm{ml}^{-1}\right)$ was added to culture medium, then total RNAs were prepared after various time intervals $(0,10,30$ and 60 min). The Northern blots included ${ }^{32} \mathrm{P}$-labelled $300 \mathrm{bp}$ DNA fragments that contained the BS190 RNA gene. 


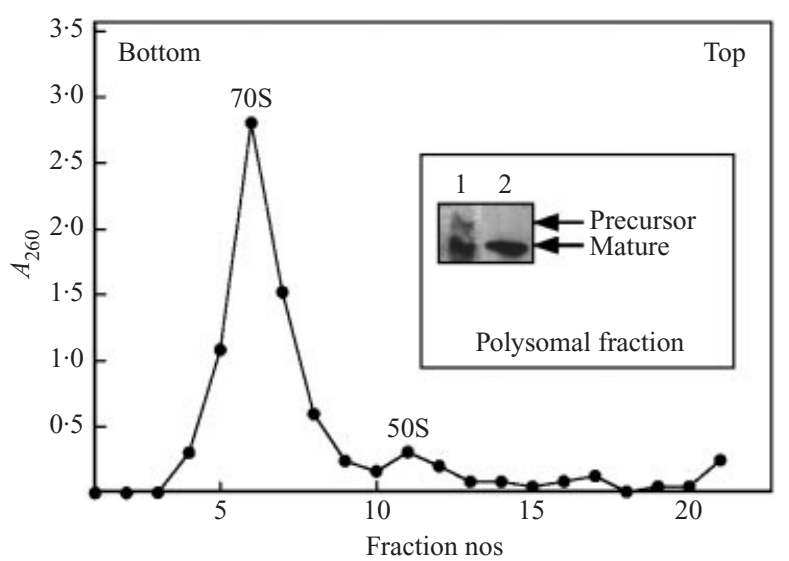

$\begin{array}{lllllllllllllllllll}1 & 2 & 3 & 4 & 5 & 6 & 7 & 8 & 9 & 10 & 11 & 12 & 13 & 14 & 15 & 16 & 17 & 20 & 21\end{array}$
Fig. 6. Subcellular localization of BS190 RNA. Cell lysates of $B$. subtilis 168 (trpC2) prepared from samples taken in the vegetative phase of growth were applied to a $5-20 \%$ sucrose gradient. Samples were collected from the Top of the gradient as 21 fractions of $500 \mu \mathrm{l}$ each (lanes 1-21, bottom panel), and the polysomal fraction was recovered from the Bottom of the tube (inset). The BS190 RNA (mature) and BS201 RNA (precursor) in each fraction were detected after electrophoresis through denaturing polyacrylamide gels containing $6 \mathrm{M}$ urea followed by Northern-blotting using 5 '-end ${ }^{32} \mathrm{P}$-labelled DNA fragments that encoded BS201 RNA. The polysomal fraction was recovered from the Bottom of the tube and RNAs were collected for Northern blotting (lane 2, inset), as described in Methods. BS190 RNA (mature) and its precursor, BS201 RNA, were identified according to the bands seen in the sample of total RNA before sucrosegradient centrifugation (lane 1, inset) and size markers.
BS190 RNA and BS201 RNA are 190 and $201 \mathrm{nt}$ in length, respectively. The difference in size between the two RNAs is due to the heterogeneity at the $5^{\prime}$ end. A promoter structure was identified (Fig. 1B) upstream of the $5^{\prime}$ end of the BS201 RNA gene, which showed sequence homology with the consensus for other promoters in $B$. subtilis that are regulated by RNA polymerase containing $\sigma^{\mathrm{A}}$. Moreover, Northern blots of total RNA that was separated on denaturing agarose gels and probed with a BS201-RNA-gene-specific DNA fragment did not produce any RNA molecules larger than the two sRNAs described above (data not shown). This finding suggests that BS201 RNA and BS190 RNA are independently expressed rather than them being the stable degradation products of a larger polycistronic RNA encoded by the aspS cluster, or processed leaders of downstream genes. Fig. 1 shows that the RNAencoding region is located in the front-half of the aspS-yrv $M$ intergenic region. However, when the DNA fragment encompassing nucleotides 720-1020 (Fig. 1B) was used as a probe no band was obvious (data not shown). Therefore, it is unlikely that BS190 RNA arises from a larger RNA, but is instead derived from BS201 RNA. Larger RNAs lack a protein-coding capacity and a Shine-Dalgarno sequence and it seems that they exert their action mainly or exclusively at the RNA level. Here, the gene encoding both BS190 RNA and BS201 RNA is designated as $b s r A$ ( $\underline{B}$. subtilis small $\underline{\mathrm{R} N A}-\underline{\mathrm{A}})$.

\section{Processing of BS201 RNA at its 5' end to form BS190 RNA}

Computer-aided analysis predicted that BS190 RNA and BS201 RNA can be folded into the tight double helix structure shown in Fig. 5A. Two stem-loop structures are found in the middle of the hairpin structure. The $5^{\prime}$ end of BS201 RNA contains an $11 \mathrm{nt}$ sequence that does not form base-pairs and which is absent in BS190 RNA. The different lengths of the two RNAs at the $5^{\prime}$ end raises the notion that RNA processing from the primary transcript (BS201 RNA) produces BS190 RNA. To monitor the processing of BS201 RNA, exponentially growing $B$. subtilis cells were exposed to rifampicin. Total RNA was then extracted from these cultures and Northern blotted. BS190 RNA and BS201 RNA were actively expressed under exponential growth conditions (Fig. 5B, lane 1), as deduced from the promoter sequence. After the addition of rifampicin, the BS201 RNA band disappeared while the intensity of the BS190 RNA band concomitantly increased. Densitometry demonstrated that $30 \mathrm{~min}$ after the addition of rifampicin, $90 \%$ of BS201 RNA had been converted into BS190 RNA (Fig. $5 \mathrm{~B}$, lane 3). This processing of BS201 RNA was not inhibited in the B. subtilis RNaseIII conditional mutant (BG218) in which the RNaseIII gene functions only partially (data not shown). Moreover, the $11 \mathrm{nt}$ at the $5^{\prime}$ end of BS201 RNA had no significant homology with the consensus sequence for recognition by the RNaseP enzyme. Therefore, the enzyme participating in BS201 RNA processing remains unknown.

\section{Effects of depletion of BS190 RNA on cell growth}

To study the cellular functions of BS190 RNA, we constructed a null-mutant in which the gene encoding BS190 RNA was replaced with the kanamycin-resistance gene, as described in Methods. The colony size of the $\triangle$ BS190 RNA mutant on LB agar is smaller that that of the wild-type (data not shown). Neither BS190 RNA nor BS201 RNA was expressed under exponential growth conditions (Fig. 2A, lanes 1 and 2). The absence of intracellular BS190 RNA (BS201 RNA) resulted in a decreased growth rate (Fig. 2B) and a lower maximum cell yield in LB broth (Fig. 2B). 


\section{Subcellular localization of BS190 RNA}

Among the sRNAs that have been characterized previously, several have been implicated in translation (Altuvia et al., 1998; Majdalani et al., 1998; Muto et al., 1998; Tetart \& Bouche, 1992). To examine the possibility that either BS190 RNA or BS201 RNA is associated with ribosomes, cell lysates prepared from exponentially growing cells were separated by sucrose density-gradient centrifugation. RNA was prepared from each fraction and Northern blotted to detect BS190 RNA and BS201 RNA. Quantitative densitometric data indicated that approximately $60 \%$ of the total BS190 RNA sedimented with polysomes (Fig. 6B, inset) and about 30\% was detected in the $70 \mathrm{~S}$ monomeric ribosomes (Fig. 6). No band corresponded to BS201 RNA in neither the 70S monosomal (Fig. 6) nor the polysomal fraction (Fig. 6, lane 2, inset). These results suggest that BS190 RNA specifically associates or interacts with ribosomes during translation. Consequently, BS190 RNA, rather than BS201 RNA, is active or functional.

In this study, we have identified and characterized a novel sRNA from B. subtilis (BS190 RNA) that is generated by $5^{\prime}$-end processing of a larger precursor (BS201 RNA) that accumulates during vegetative growth. A search of the non-redundant nucleic-acidsequence database using BLAST revealed that RNAs related to BS201 and BS190 appear to be encoded in the genomes of Bacillus halodurans (nucleotide nos 1350677-1350868) and Listeria monocytogenes/innocua (nucleotide nos 1550993-1550786/15465401546331, respectively). For example, the nucleotide sequence of the corresponding region in B. halodurans shows $65 \%$ identity to that of BS190 RNA. Moreover, this region is located in front of the BH1255 gene that is a homologue of the $B$. subtilis yrvM gene.

To date, at least 10 sRNAs have been identified in $E$. coli. Recently, 24 candidate intergenic regions in E. coli have been proposed as possibly encoding novel sRNAs (Wassarman et al., 2001). Of these 24 intergenic regions, Wassarman et al. (2001) confirmed that 14 encode sRNAs, by using micro-array technology and Northern hybridization. Based on the DNA sequence data for the whole genome of $B$. subtilis, we selected 123 regions of $>500 \mathrm{nt}$ in length as candidates for non-coding RNAencoding regions in $B$. subtilis. These regions were located between two ORFs, but they lacked a proteincoding capacity and a Shine-Dalgarno sequence. Among these regions, we have found (by using Northern blotting) that the yocl-yocJ intergenic region can produce an sRNA of $203 \mathrm{nt}$ (Ando et al., 2002). However, we have not found a sequence corresponding to this RNA adjacent to the E. coli homologues of yocI and yocJ.

\section{ACKNOWLEDGEMENTS}

This work was supported by Grants-in-Aid for the Scientific Research on Priority Area (C) 'Genome Biology' and Research Abroad to M.F. from the Ministry of Education, Culture,
Sports, Science and Technology of Japan, and by a grant from the Mitsubishi Chemical Corporation Fund. The authors also thank N. Foster for critically reading the manuscript.

\section{REFERENCES}

Altuvia, S. \& Wagner, E. G. H. (2000). Switching on and off with RNA. Proc Natl Acad Sci U S A 97, 9824-9826.

Altuvia, S., Weinstein-Fischer, D., Zhang, A., Postow, L. \& Storz, G. (1997). A small, stable RNA induced by oxidative stress: role as a pleiotropic regulator and antimutator. Cell 90, 43-53.

Altuvia, S., Zhang, A., Argaman, L., Tiwari, A. \& Storz, G. (1998). The Escherichia coli OxyS regulatory RNA represses fhlA translation by blocking ribosome binding. EMBO J 17, 60696075.

Ando, Y., Asari, S., Suzuma, S., Yamane, K. \& Nakamura, K. (2002). Expression of a small RNA, BS203 RNA, from the yocI-yocJ intergenic region of Bacillus subtilis genome. FEMS Microbiol Lett 207, 29-33.

Argaman, L., Hershberg, R., Vogel, J., Bejerano, G., Wagner, E. G. H., Margalit, H. \& Altuvia, S. (2001). Novel small RNAencoding genes in the intergenic regions of Escherichia coli. Curr Biol 11, 941-950.

Bernstein, H. D., Poritz, M. A., Strub, K., Hoben, P. J., Brenner, S. \& Walter, P. (1989). Model for signal sequence recognition from amino-acid sequence of $54 \mathrm{~K}$ subunit of signal recognition particle. Nature 340, 482-486.

Bourgaize, D. B. \& Fournier, M. J. (1987). Initiation of translation is impaired in E. coli cells deficient in 4.5S RNA. Nature 325, 281-284.

Brown, S. (1987). Mutations in the gene for EF-G reduce the requirement for 4.5S RNA in the growth of E. coli. Cell 49, 825-833.

Brown, S. \& Fournier, M. J. (1984). The 4.5S RNA gene of Escherichia coli is essential for cell growth. J Mol Biol 178, 533-550.

Chen, J.-H., Le, S.-Y., Shapiro, B., Currey, K. M. \& Maizel, J. V. (1990). A computational procedure for assessing the significance of RNA secondary structure. Comput Appl Biosci 6, 7-18.

Dandekar, T. \& Hentze, M. W. (1995). Finding the hairpin in the haystack: searching for RNA motifs. Trends Genet 11, 45-50.

Eddy, S. R. (1999). Noncoding RNA genes. Curr Opin Genet Dev 9, 695-699.

Erdmann, V. A., Barciszewska, M. Z., Szymanski, M., Hochberg, A., de Groot, N. \& Barciszewski, J. (2001). The non-coding RNAs as riboregulators. Nucleic Acids Res 29, 189-193.

Gorodkin, J., Knudsen, B., Zwieb, C. \& Samuelsson, T. (2001). SRPDB (Signal Recognition Particle Database). Nucleic Acids Res 29, 169-170.

Guerout-Fleury, A. M., Shazand, K., Frandsen, N. \& Stragier, P. (1995). Antibiotic-resistance cassettes for Bacillus subtilis. Gene 167, 335-336.

Jovine, L., Hainzl, T., Oubridge, C., Scott, W. G., Li, J., Sixma, T. K., Wonacott, A., Skarzynski, T. \& Nagai, K. (2000). Crystal structure of the Ffh and EF-G binding sites in the conserved domain IV of Escherichia coli 4.5S RNA. Structure Fold Des 8, 527-540.

Kirsebom, L. A. (2001). Escherichia coli ribonuclease P. Methods Enzymol 342, 77-92.

Lankenau, S., Corces, V. G. \& Lankenau, D. H. (1994). The Drosophila micropia retrotransposon encodes a testis-specific antisense RNA complementary to reverse transcriptase. Mol Cell Biol 14, 1764-1775. 
Le, S.-Y., Chen, J.-H. \& Maizel, J. V. (1989). Thermodynamic stability and statistical significance of potential stem-loop structures situated at the frameshift sites of retroviruses. Nucleic Acids Res 17, 6143-6152.

Lowe, T. M. \& Eddy, S. R. (1997). tRNAscan-SE: a program for improved detection of transfer RNA genes in genomic sequence. Nucleic Acids Res 25, 955-964.

Majdalani, N., Cunning, C., Sledjeski, D., Elliott, T. \& Gottesman, S. (1998). DsrA RNA regulates translation of RpoS message by an anti-sense mechanism, independent of its action as an antisilencer of transcription. Proc Natl Acad Sci U S A 95, 12462-12467.

Muto, A., Ushida, C. \& Himeno, H. (1998). A bacterial RNA that functions as both a tRNA and an mRNA. Trends Biochem Sci 23, $25-29$.

Nakamura, K., Nishiguchi, M., Minemura, M., Honda, K. \& Yamane, K. (1994). Small cytoplasmic RNA of Bacillus brevis: transcriptional and phylogenetic analysis. Microbiology 140, 493-498.

Nakamura, K., Fujii, Y., Shibata, T. \& Yamane, K. (1999). Depletion of Escherichia coli 4.5S RNA leads to an increase in the amount of protein elongation factor EF-G associated with ribosomes. Eur J Biochem 259, 543-550.

Nuyts, S., Van Mellaert, L., Lambin, P. \& Anne, J. (2001). Efficient isolation of total RNA from Clostridium without DNA contamination. J Microbiol Methods 44, 235-238.

Poritz, M. A., Strub, K. \& Walter, P. (1988). Human SRP RNA and E. coli $4 \cdot 5 \mathrm{~S}$ RNA contain a highly homologous structural domain. Cell 55, 4-6.

Rivas, E., Klein, R. J., Jones, T. A. \& Eddy, S. R. (2001). Computational identification of noncoding RNAs in E. coli by comparative genomics. Curr Biol 11, 1369-1373.
Sambrook, J., Fritsch, E. F. \& Maniatis, T. (1989). Molecular Cloning: a Laboratory Manual, 2nd edn. Cold Spring Harbor, NY : Cold Spring Harbor Laboratory.

Shibata, T., Fujii, Y., Nakamura, Y., Nakamura, K. \& Yamane, K. (1996). Identification of protein synthesis elongation factor $\mathrm{G}$ as a 4.5S RNA-binding protein in Escherichia coli. J Biol Chem 271, 13162-13168.

Storz, G. (1999). An RNA thermometer. Genes Dev 13, 633-636. Stroud, R. M. \& Walter, P. (1999). Signal sequence recognition and protein targeting. Curr Opin Struct Biol 9, 754-759.

Tetart, F. \& Bouche, J. P. (1992). Regulation of the expression of the cell-cycle gene $f t s Z$ by DicF antisense RNA. Division does not require a fixed number of FtsZ molecules. Mol Microbiol 6, 615-620.

Wassarman, K. M. \& Storz, G. (2000). 6S RNA regulates E. coli polymerase activity. Cell 101, 613-623.

Wassarman, K. M., Zhang, A. \& Storz, G. (1999). Small RNAs in Escherichia coli. Trends Microbiol 7, 37-45.

Wassarman, K. M., Repoila, F., Rosenow, C., Storz, G. \& Gottesman, S. (2001). Identification of novel small RNAs using comparative genomics and microarrays. Genes Dev 15, 16371651.

Wightman, B., Ha, I. \& Ruvikun, G. (1993). Posttranscriptional regulation of the heterochronic gene lin-14 by lin-4 mediates temporal pattern formation in C. elegans. Cell 75, 855-862.

Zhang, A., Altuvia, S., Tiwari, A., Argaman, L., Hengge-Aronis, R. \& Storz, G. (1998). The OxyS regulatory RNA represses rpoS translation and binds the $\mathrm{Hfq}$ (HF-I) protein. EMBO J 17, 6061-6068.

Received 6 February 2002; revised 25 April 2002; accepted 1 May 2002. 